\title{
Determination of Particle Size Distribution by FMR Measurements
}

\author{
Walter S. D. Folly and Ronaldo S. de Biasi \\ Departamento de Engenharia Mecânica e de Materiais \\ Instituto Militar de Engenharia \\ Praça General Tibúrcio, 80 \\ 22290-270 Rio de Janeiro, RJ, Brazil \\ E-mail: walfolly@hotmail.com
}

Received on 21 December, 2000

\begin{abstract}
Knowledge of particle size distribution is very important for the study of magnetic fluids, magnetic powders and other magnetic systems. In this work, we describe a simple method for its determination from FMR measurements. The method was applied to the case of $\mathrm{MgFe}_{2} \mathrm{O}_{4}$ precipitates in $(\mathrm{Mg}, \mathrm{Fe}) \mathrm{O}$.
\end{abstract}

\section{Introduction}

When a magnetic system is an ensemble of particles of several sizes, the FMR spectrum measured at intermediate temperatures is the sum of two absorption spectra [1], one due to superparamagnetic particles and another due to ferromagnetic particles; in addition, the anisotropy of the spectrum due to ferromagnetic particles increases as the temperature is decreased. At sufficiently low temperatures, the superparamagnetic spectrum vanishes and only the ferromagnetic spectrum is observed, since all particles have their magnetic dipole moments blocked. At high temperatures, all the magnetic dipole moments are unblocked and only the superparamagnetic spectrum is observed. Measuring the relative intensities of the two spectra and the anisotropy field of the ferromagnetic spectrum as functions of the temperature, is possible to determine the particle size distribution of the system.

\section{Theory}

Our method is based on the assumption that the intensity of the superparamagnetic spectrum is proportional to the number of particles whose volumes are smaller than a critical value, which is temperature dependent.

Thus, we have:

$$
\int_{0}^{D_{c}(T)} D^{3} \cdot P(D) \cdot d D=C \cdot I_{S P}
$$

were $P(D)$ is the particle size distribution, $D_{c}(T)$ is the critical diameter, $I_{S P}(T)$ is the intensity of superparamagnetic absorption peak and $C$ is a proportionality constant.

According to the model proposed by de Biasi and Devezas [2], the anisotropy field of an ensemble of small magnetic particles is, in the case of cubic lattices, given by:

$$
H_{A}^{S P}=H_{A} \cdot f_{c}(x)
$$

where

$$
\begin{gathered}
f_{c}(x)=\frac{1-10 \cdot x^{-1} \cdot \operatorname{coth}(x)+45 \cdot x^{-2}-105 \cdot x^{-3} \cdot \operatorname{coth}(x)+105 \cdot x^{-4}}{\operatorname{coth}(x)-x^{-1}} \\
x=\frac{I_{S} \cdot V \cdot H}{k T}
\end{gathered}
$$


where $I_{S}$ is the intrinsic magnetization of the particles, $V$ is the particle volume and $H$ is the applied magnetic field. Fig. 1 shows a plot of Eq. (3a) as a function of $x$.
Assuming spherical particles and considering Eq. (3b), Eq. (1) can be rewritten in the following differential form:

$$
P\left(D_{c}(T)\right)=C \frac{\pi I_{S} H_{0}}{2 x_{c} k}\left[\frac{1}{1-\frac{T}{I_{S}}\left(\frac{\partial I_{S}}{\partial T}\right)_{T}}\right]\left(\frac{\pi I_{S} H_{0}}{6 x_{c} k T}\right)^{1 / 3} \cdot\left(\frac{\partial I_{S P}}{\partial T}\right)_{T}
$$

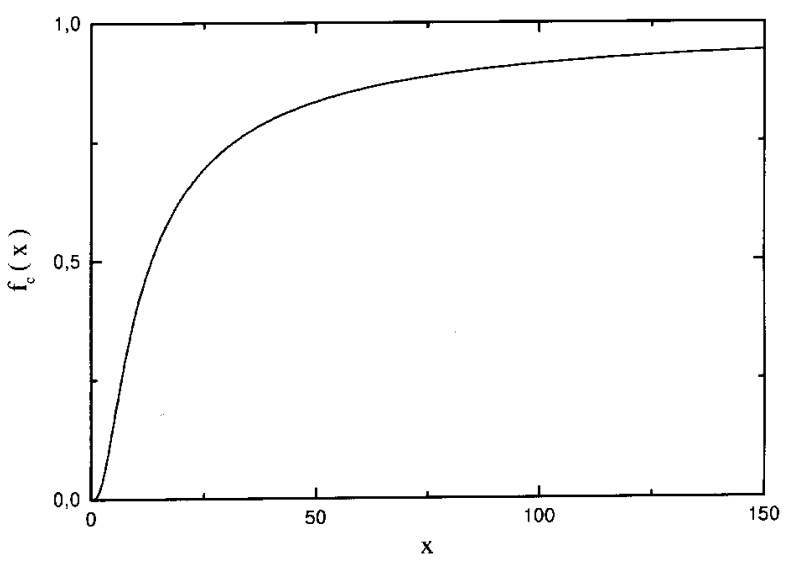

Figure 1. The function $f_{c}(x)$.

If the intrinsic magnetization $I_{S}$ remains approximately constant in the temperature range of interest, we may assume:

$$
\frac{\partial I_{S}}{\partial T} \approx 0
$$

and Eq. (4) can be simplified to

$$
P\left(D_{c}(T)\right)=C \frac{\pi I_{S} H_{0}}{2 x_{c} k}\left(\frac{\pi I_{S} H_{0}}{6 x_{c} k T}\right)^{1 / 3} \cdot\left(\frac{\partial I_{S P}}{\partial T}\right)_{T}
$$

where $H_{0}$ is the superparamagnetic resonance field and $x_{c}$ is given by:

$$
x_{c}=\frac{\pi I_{S} H_{0}<D>^{3}}{6 k<T_{c}>}
$$

In order to find the value of $\langle D\rangle$ in Eq. (6), we fit the function

$$
H_{A}^{S P}=H_{A} \cdot f_{c}\left(\frac{A}{T}\right)
$$

to the experimental magnetic anisotropy data and substitute the value of constant $A$ in the following equation:

$$
<D>=\left(\frac{6 k A}{\pi I_{S}<H_{0}^{\text {ferr }}>}\right)^{1 / 3}
$$

The value of average critical temperature, $\left\langle T_{c}\right\rangle$, may be calculated from the experimental data on the intensity of the superparamagnetic spectrum using Eqs. (9) and (10):

$$
<T_{c}>=\frac{\int_{0}^{\infty} T P(T) d T}{\int_{0}^{\infty} P(T) d T}
$$

where

$$
P(T)=C\left(\frac{1}{T}\right)^{1 / 3}\left(\frac{\partial I_{S P}}{\partial T}\right)_{T}
$$

Once the value of $x_{c}$ is determined, we can to convert $P(T)$ to $P\left(D_{c}(T)\right) \equiv P(D)$ using the following equation:

$$
D_{c}(T)=\left(\frac{6 x_{c} k T}{\pi I_{S} H_{0}}\right)^{1 / 3} \equiv D
$$

The last step is the normalization of the particle size distribution by the determination of proportionality constant $C$ that appears in Eq. (10), using a normalization equation such as Eq. (12),

$$
\int_{0}^{\infty} P(D) d D=1
$$

\section{Study of magnesioferrite par- ticles in magnesiowüstite}

We used the method above to investigate the size distribution of magnesioferrite $\left(\mathrm{MgFe}_{2} \mathrm{O}_{4}\right)$ precipitates in magnesiowüstite $(\mathrm{Mg}, \mathrm{Fe}) \mathrm{O}[3]$. The average particle sizes measured in this system ranged from a few nanometers to tenths of nanometers, depending on temperature and annealing time.

In the present work, magnesiowüstite $(\mathrm{Mg}, \mathrm{Fe}) \mathrm{O}$ was prepared by packing a single crystal of $\mathrm{MgO}$ in a $\mathrm{MgO}-$ $\mathrm{Fe}_{2} \mathrm{O}_{3}$ powder mixture containing 2,2 mol\% $\mathrm{Fe}$, firing at $1673 \mathrm{~K}$ for two weeks and quenching into cold water. The single crystal was removed, cleaned and annealed at $973 \mathrm{~K}$ for 6 hours to precipitate the magnesioferrite 
$\left(\mathrm{MgFe}_{2} \mathrm{O}_{4}\right)$ phase. The precipitates are coherent with the $(\mathrm{Mg}, \mathrm{Fe}) \mathrm{O}$ matrix.

Magnetic resonance spectra were measured in the temperature range from $18 \mathrm{~K}$ to $300 \mathrm{~K}$ using a Bruker $\mathrm{X}$-band spectrometer and a Displex cooling system. The intensity of the superparamagnetic spectra was calculated from experimental data taking the product of the square of the linewidth by the amplitude of the spectrum [4]. The anisotropy field was obtained from the ferromagnetic spectra by computing the difference of the resonance fields with the magnetic field aligned along the [100] and [110] crystal directions.

The temperature dependence of the intensity of the superparamagnetic is shown in Fig. 2. Figs. 3 and 4 show, respectively, the critical temperature distribution [see Eq. (10)] and the anisotropy field of particles versus inverse temperature.

The curve shown in Fig. 4 was obtained by fitting Eq. (7) to the experimental data, taking $A$ and $H_{A}$ as adjustable parameters.

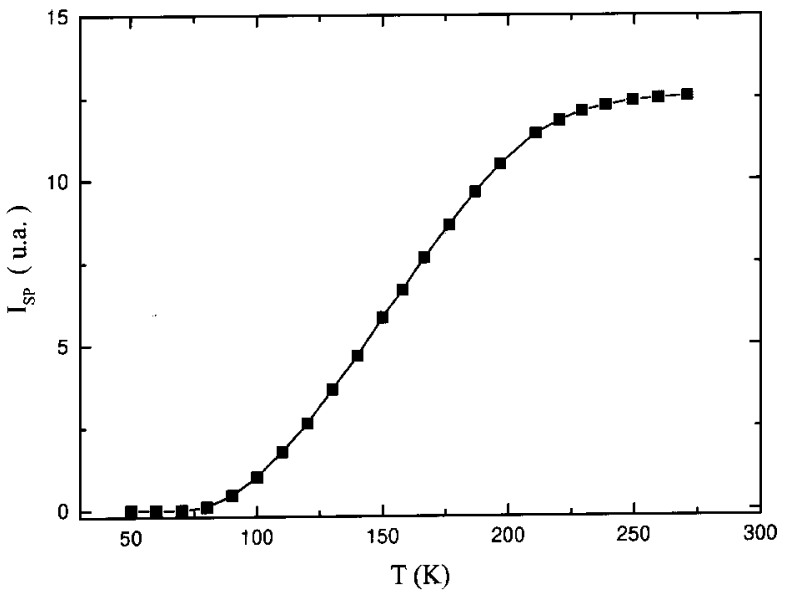

Figure 2. Temperature dependence of the intensity of the superparamagnetic spectrum.

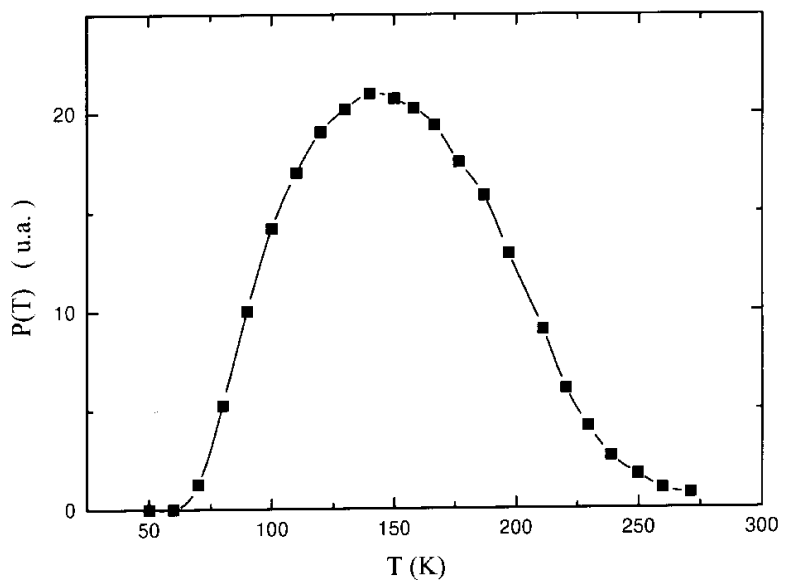

Figure 3. Critical temperature distribution.

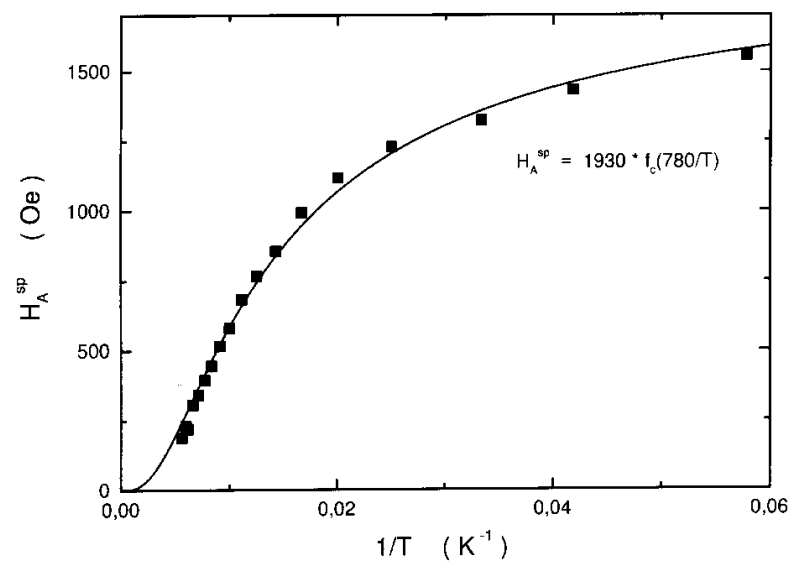

Figure 4. Temperature dependence of the anisotropy field.

The solid line in Fig. 4 corresponds to the function:

$$
H_{A}^{S P}=H_{A} \cdot f_{c}\left(\frac{A}{T}\right)
$$

with

$$
A=780 K, \quad H_{A}=1930 O e
$$

According to Eqs. (8) and (9), we have:

$$
<D>=5.86 \mathrm{~nm} \quad<T_{c}>=152.15 \mathrm{~K}
$$

Substituting these values in Eq. (6), we find:

$$
x_{c}=5.13
$$

Now, we can calculate the critical diameters relative to each temperature using Eq. (11), obtaining the unnormalized particle size distribution $P(D)$. Using the normalization equation [Eq. (12)], we obtain the normalized particle size distribution shown in Fig. 5. The calculated value of the constant $C$ is:

$$
C=31.46 \mathrm{~nm}^{-1}
$$

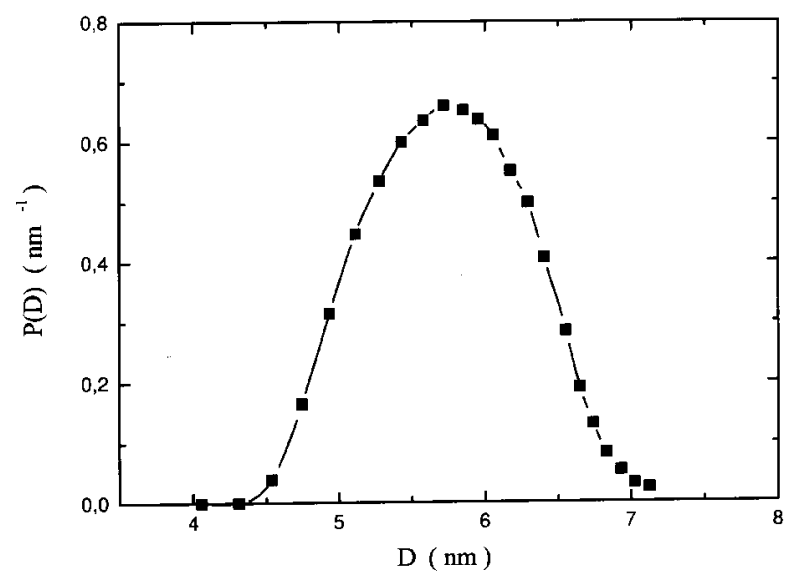

Figure 5. Particle size distribution for $\mathrm{MgFe}_{2} \mathrm{O}_{4}$ in $(\mathrm{Mg}, \mathrm{Fe}) \mathrm{O}$ annealed at $973 \mathrm{~K}$ for $6 \mathrm{~h}$. 


\section{Conclusions}

The results reported above are in agreement with those reported by Wirtz and Fine [3] who used the technique of electron microscopy to determine particle size distributions in this same system of magnetic particles.

\section{References}

[1] R.S. de Biasi and T.C. Devezas, Proceedings of the Ninth International Colloquium on Magnetic Films and
Surfaces, Poznan, Poland, p. 38 (1979).

[2] R.S. de Biasi and T.C. Devezas, J. Appl. Phys. 49, 4 (1978).

[3] G.P. Wirtz and M.E. Fine, J. Am. Ceram. Soc. 51, 402 (1968).

[4] J.E. Wertz and J.R. Bolton, Electron Spin Resonance, McGraw-Hill, 1967, p. 34. 